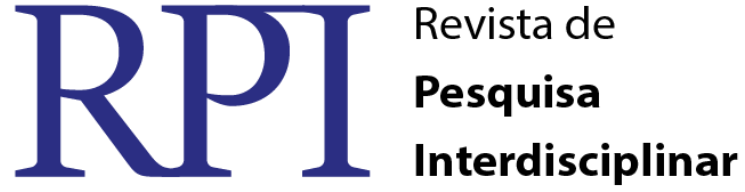

\section{A FORMAÇÃO CONTINUADA NO ENSINO FUNDAMENTAL II: CASOS E DESCASOS NA ESCOLA MUNICIPAL FÉLIX PEREIRA DOS REIS}

(SANTA INÊS-PB)

\author{
Maria Aparecida Gomes de Sousa ${ }^{1}$ \\ Rodrigo Ceballos ${ }^{1}$
}

\begin{abstract}
RESUMO
Pensar sobre a formação continuada de professores é tema de grande importância, pois pensar sobre formação continuada é pensar também sobre a melhoria da qualidade da educação no Brasil, visto que investir na qualificação profissional docente é investir também na construção de um saber pautado em valores como igualdade e na construção de uma sociedade democrática. Nesse sentido, o presente artigo tem como objetivo refletir sobre formação continuada de professores da Escola Municipal Félix Pereira dos Reis, situada no município de Santa Inês-PB. Para tal, fizemos a análise de dados do IDEB, do Censo Escolar e do Projeto Político da escola, além de revisão bibliográfica. Quanto à forma de abordagem, os dados foram analisados a partir de uma perspectiva qualitativa. Como resultado, entendemos que a formação continuada de professores permite um vasto campo de análise e debates, e que debruçar-se sobre este tema possibilita o aperfeiçoamento das práticas pedagógicas no intuito de atender os avanços almejados referentes a qualidade do ensino.
\end{abstract}

Palavras-chave: Ensino; Formação continuada; Escola.

\begin{abstract}
Thinking about the teacher's continued education is an important topic to think over the improvement of the quality of Brazilian's education. Therefore invest on professional qualification means investments in knowledge based in values like equality and the built of a democratic society. The aim of this article is to consider the teacher's continued education in the Félix Pereira dos Reis Municipal School, located in Santa Ines City, Paraiba State. To achieve our goals we analyzed IDEB's data, School's Cense and the School's Political Project as primary sources; We also made a bibliographical review. We've analyzed the data in a qualitative perspective. We consider that the teacher's continued education provides a wide analysis and debates fields. As a result of this perspective and analysis, this subject provides improvements in pedagogical practices to achieve educational quality.
\end{abstract}

Keywords: Education, Continued Education, School.

\section{INTRODUÇÃOO}

\footnotetext{
${ }^{1}$ Universidade Federal de Campina Grande - UFCG.
} 
A quantidade de questões relativas à formação continuada de professores é muito grande, e isso se dá pelo fato da escola ser um espaço de constantes transformações e saberes múltiplos. Ensinar é uma tarefa desafiadora, pois segundo Alarcão (2001, p. 18) "a escola tem a função de preparar cidadãos, mas não pode ser pensada apenas como tempo de preparação para a vida. Ela é a própria vida, um local de vivência da cidadania”. Essas vivências não são homogêneas, diferenciam-se no momento em que sofrem influências da sociedade na qual os indivíduos estão inseridos, influências sociais, políticas e econômicas.

Diante das transformações da sociedade atual, da velocidade com que as informações são produzidas e da forma com que elas chegam aos educandos, e consequentemente das mudanças de valores educacionais e sociais frutos dessa nova forma de se viver na modernidade, se faz necessário à prática docente acompanhar os progressos tecnológicos e também os científicos de maneira a refletir e ressignificar essas transformações na prática docente, pois "não podemos deixar de considerar o avanço das tecnologias de informação e comunicação que não só ampliam tempos e espaços de aprendizagem, como também produzem modificações nos modos de aprender dos sujeitos" (ALTENFELDER, 2005, p.32).

É neste sentido que norteia-se este trabalho: na necessidade de se pensar o contínuo aperfeiçoamento dos professores através do investimento em sua formação, de analisar os reflexos desse investimento na prática profissional, como também na análise de possíveis dificuldades enfrentadas no âmbito escolar e na vida cotidiana que podem vir a ser fatores de dificuldade de tal aperfeiçoamento. Assim, corroboramos com Altenfelder (2005, p. 2) quando ela nos diz que,

Formação de professores, inicial ou continuada, constitui-se, portanto, tema de importância para estudo e pesquisa, no sentido de se buscar promover as condições para que a escola cumpra efetivamente sua função de ensinar e formar cidadãos, que sejam ativos na construção de uma sociedade caracterizada por eqüidade e justiça.

É entendendo a importância de constante diálogo com as questões que norteiam a formação continuada de professores que justificamos a relevância dessa pesquisa. Para tal, utilizaremos de revisão bibliográfica para tecer reflexões sobre o campo teórico e as abordagens referentes a formação continuada no Brasil, suas transformações e dinamismo. Como forma de abordagem, nos situaremos numa perspectiva qualitativa, pois corroboramos com Minayo quando nos diz que:

A pesquisa qualitativa responde a questões muito particulares. Ela se ocupa, nas Ciências Sociais, com um nível de realidade que não pode ou não deveria ser quantificado. Ou 
seja, ela trabalha com o universo dos significados, dos motivos, das aspirações, das crenças, dos valores e das atitudes. (2009, p. 21)

Em se tratando de produções e representações humanas, este estudo dificilmente poderia ser traduzido apenas em estatísticas ou quantificada. Partindo desse olhar, analisamos o quadro de professores da Escola Municipal de Ensino Fundamental Félix Pereira dos Reis, situada na Zona Urbana da cidade de Santa Inês-PB; mais especificadamente os professores do Ensino Fundamental II, correspondente às turmas do $6^{\circ}$ ao $9^{\circ}$ anos, assim como o seu nível de formação, as áreas em que atuam, o tipo de aperfeiçoamento profissional oferecidos aos mesmos (formação continuada), caso exista, e os reflexos disso no desempenho dos alunos. Para tal usamos como documentos de análise o Projeto Político Pedagógico da referida escola, o Censo Escolar de 2018 e também os dados do IDEB (Índice de Desenvolvimento da Educação Básica) para obtenção de informações sobre o rendimento escolar dos alunos do Ensino Fundamental nos últimos anos. A Escola, em análise, está situada na Rua Vereador José Pereira da Silva, no 165, na cidade supracitada . Foi criada pelo poder executivo através do Decreto de número 19/90 de 26 de julho de 1990, código do INEP: 25028324, subordinada a Secretaria Municipal de Educação e Cultura do município de Santa Inês -PB. Funciona em dois turnos, manhã e tarde, nas seguintes modalidades: Educação Infantil pela manhã, Ensino Fundamental I $\left(1^{\circ}\right.$ ao $\left.5^{\circ}\right)$ e II $\left(6^{\circ}\right.$ ao $\left.9^{\circ}\right)$ pela tarde.

Seu quadro de funcionários é composto por 18 Professores, sendo todos licenciados. Tem como diretor Raimundo Nonato Martins e como vice-diretor Maria da Conceição Sá Pereira. Não dispõe de pedagogo ou psicopedagogo para acompanhar as questões pedagógicas da escola.

Quanto a importância de um pedagogo nas instituições escolares Pimenta (1988) nos $\operatorname{diz}$,

[...] a posição que temos assumido é a de que a escola pública necessita de um profissional denominado pedagogo, pois entendemos que o fazer pedagógico, que ultrapassa a sala de aula e a determina, configura-se como essencial na busca de novas formas de organizar a escola para que esta seja efetivamente democrática. A tentativa que temos feito é a de avançar da defesa corporativista dos especialistas para a necessidade política do pedagogo, no processo de democratização da escolaridade (PIMENTA, 1988, p. 7-8).

Na realidade, o município, como um todo não conta com os serviços de um pedagogo, e esta não é uma peculiaridade apenas da escola em análise. Reconhecemos, com isso, a perda dos profissionais e alunos, pois entendemos a importância e necessidade de um profissional 
que compreenda e trate das questões políticas e educacionais na escola.O pedagogo seria o articulador das rotas que levariam a busca por uma educação que valorize e respeite o lugar social dos alunos e as singularidades do corpo docente que compõe a instituição e, com isso, se traçariam metas para a consolidação de um ensino-aprendizagem mais significativo e que contemple as reais necessidades de seu público.

Sobre o número de alunos, segundo dados do Censo Escolar de 2019, atualmente a escola atende uma demanda de 253 alunos, em matrícula inicial. Salienta-se que esse número pode ser alterado no cadastro do Censo devido a transferências, admissão e evasões ocorridas durante o decorrer do ano. Desse número total, estão matriculados no Ensino Fundamental II, 91 alunos , sendo 31 alunos no $6^{\circ}$ ano, 20 alunos no $7^{\circ}$ ano, 20 alunos no $8^{\circ}$ ano e 20 alunos no $9^{\circ}$ ano (vide Anexo I). Ainda segundo dados do Censo Escolar, a escola dispõe de um quadro geral de 18 professores, todos concursados. Desses, oito lecionam no Ensino Fundamental II (vide Anexo II). Todos possuem nível superior e atuam na área de sua formação.

Diante do exposto, entendemos que refletir sobre a existência ou a ausência da formação continuada em uma instituição de ensino e os reflexos na qualidade da educação e no desenvolvimento interpessoal de alunos e professores é instigante e foi o que norteou a realização dessa pesquisa.

Procuramos asseverar que o ambiente escolar é considerado o lugar propício às investigações e descobertas da qualidade do ensino e da aprendizagem validando os desafios da experiência escolar como forma de aprender uma educação de melhor qualidade, acreditando que o professor precisa atualizar-se e buscar constantemente novas perspectivas de ensino.

\section{A FORMAÇÃO CONTINUADA DE PROFESSORES: TEORIA E PRÁTICA}

Entendemos a formação continuada como aspecto fundamental para a melhoria da prática docente, pois através desta o professor desenvolve um espírito crítico-reflexivo que desencadeia numa prática dotada de maior autonomia. Este olhar compreende a formação docente como algo complexo que perpassa o simples ato de transmitir conhecimentos, mas que a analisa em sua amplitude e complexidade, visando a obtenção de um ensino de qualidade, construtor de senso crítico e democrático. Assim, corroboramos com Freire quando nos diz que: 
Uma das tarefas mais importantes da prática educativo-crítico é propiciar as condições em que os educandos em suas relações uns com os outros e todos com os professores ou professoras ensaiam a experiência profunda de assumir-se como ser social e histórico como ser pensante, comunicante, transformador, criador, realizador de sonhos capaz de ter raiva porque é capaz de amar. (1996, p.41).

Entendemos assim que educação não é somente transmitir conhecimento, faz-se necessário perceber que o conhecimento não é atemporal, logo são frutos de um determinado momento histórico, sofrem influência do tipo de cultura em sociedade em que o indivíduo vive. Partindo do entendimento de que o que se ensina está em estrita relação com a identidade cultural do indivíduo e que esta é passível de transformação, Santos (1997, p.135) nos diz que “identidades são, pois, identificações em curso". Logo, é de nítida importância, tanto para quem leciona quanto para os educandos que receberão as informações, manter-se sempre informado e adquirindo novos conhecimentos, tanto de conteúdos, quanto de metodologias e materiais didáticos, estando sempre atento ao que de novo existe no campo educacional. Assim, segundo Perrenoud:

A principal ferramenta de trabalho do professor é sua pessoa, sua cultura, a relação que instaura com os alunos, individual ou coletivamente. Mesmo que a formação esteja centrada nos saberes, na didática, na avaliação, na gestão de classe e nas tecnologias, nunca deve esquecer a pessoa do professor. (2002, p.176).

O "ser" professor deve ser entendido para além de sua função de transmissor de conteúdos, pois no contato direto e diário com os alunos associa-se sua experiência profissional à pessoal. Assim, corroborando com o que nos diz Freire (1996), além de ensinar, as ciências também visam que sua prática esteja atrelada a construção de uma sociedade mais justa e igualitária, como também o despertar do olhar crítico e curioso dos alunos.

Além do que ressaltamos, o empenho individual dos profissionais em ter uma educação de qualidade é também um amparo legal garantido a todos os brasileiros na Constituição da República Federativa do Brasil de 1988, onde no artigo 206, alínea V, trata da valorização dos profissionais da educação e dos direitos que lhe são assegurados . Assim, pensando sobre a educação continuada é importante ressaltar que esta além de ser parte do empenho individual de crescimento profissional também faz parte de uma luta do poder público por uma escolarização de qualidade que envolva a todos. Neste sentido, a formação continuada também é uma exigência da LDB 9394/96, expressa no artigo a seguir: 
Art. 67. Os sistemas de ensino promoverão a valorização dos profissionais da educação, assegurando-lhes, inclusive nos termos dos estatutos e dos planos de carreira do magistério público: I - ingresso exclusivamente por concurso público de provas e títulos; II aperfeiçoamento profissional continuado, inclusive com licenciamento periódico remunerado para esse fim; III - piso salarial profissional; IV - progressão funcional baseada na titulação ou habilitação, e na avaliação do desempenho; V - período reservado a estudos, planejamento e avaliação, incluído na carga de trabalho; VI - condições adequadas de trabalho (BRASIL, 1996, p. 21).

De fundamental importância também para as questões relativas à educação destacamos o PNE (Plano Nacional e Educação), uma lei aprovada em 2014 que trata de diretrizes, estratégias e metaspara a educação no Brasil, correspondentes a dez anos após sua aprovação.O documento consta com 20 metas que contemplam todos os níveis da educação.Destacamos aqui a meta de número 16 que trata da formação continuada e pósgraduação de professores, na qual se diz :

Meta 16- Formar em nível de pós-graduação, 50\% dos professores da educação básica, até o último ano de vigência deste PNE, e garantir a todos os profissionais da Educação Básica formação continuada em sua área de atuação, considerando as necessidades, demandas e contextualizações do sistema de ensino. Objetivo: até 2024, ter metade dos professores da Educação Básica formados na pós-graduação. Objetivo 2: Até 2024, garantir que todos os professores da Educação Básica tenham acesso a um aperfeiçoamento profissional, chamado de formação continuada, em sua área de atuação. Resultado parcial: em 2017, 35,1\% dos professores da Educação Básica tinham acesso a formação continuada. Desafios: Oferecer uma formação continuada de qualidade e que supra as demandas e desafios enfrentados por cada professor, de forma a suprir as lacunas na formação inicial, ao mesmo tempo em que o matem em constante aperfeiçoamento no trabalho. É importante que o Ministério da Educação cumpra seu papel fiscalizador, assegurando uma qualidade mínima para os cursos de pósgraduação ofertados (PNE, 2019).

Segundo os dados apresentados pelo PNE até o ano de 2017, apenas 35,1\% dos professores de Educação Básica (o nível ao qual nos dedicamos nessa pesquisa) tinham acesso a educação continuada. Com isso percebemos que mesmo existindo amparo legal, este não é por si só garantia de que os professores terão acesso a esse nível de formação. Isso nos leva a refletir que a existência de políticas públicas não é sinônimo de que elasserão adequadamente 
aplicadas e que de fato os professores terão permanentemente uma formação continuada e respaldo para tal.

Para além disso, é preciso também que se valorize as individualidades, que se analise o contexto social e econômico de cada comunidade onde essas políticas devem ser aplicadas, pois pensando-se as singularidades, elas terão eficácia para assegurar o desenvolvimento de uma educação de qualidade. Segundo Parente:

Para maior entendimento da qualificação profissional do professor, é importante o relacionamento das políticas educacionais das esferas federal, estadual e municipal, reconhecendo sua realidade social e cultural por meio das leis elaboradas e desenvolvidas na dinâmica da educação brasileira. (2012, p.45)

Entende-se que se faz necessário um elo de ligação entre as leis criadas pelas esferas federal e estadual com as municipais. Estas leis devem ser ajustadas para se adequar as especificidades de cada instituição, de maneira que venha a existir eficácia na aplicação das políticas públicas voltadas para a formação continuada, e para que estas promovam mudanças reais na educação brasileira.

Essas leis, sozinhas, não garantem a qualidade que se deseja alcançar. Notadamente, a qualificação profissional além de ser uma exigência profissional é também uma experiência pessoal, uma maneira de agir reflexivamente sobre a própria atuação, um espaço de troca de experiências e diálogo, sendo assim, uma prática enriquecedora tanto para os educadores quanto para os educandos. Segundo Demo (2007, p. 11) "investir na qualidade da aprendizagem do aluno é, acima de tudo, investir na qualidade docente". Assim, para se assegurar a qualidade educacional deve-se qualificar continuamente os profissionais docentes e essa qualificação deve respeitar as vivências e as singularidades dos educadores, pois

Qualquer planejamento curricular referente à formação continuada do professor necessita registrar o ponto de vista dos próprios professores, baseados numa realidade criada por estes, considerando-os como sujeitos dotados de saberes significativos sobre o trabalho que desenvolvem na escola. Os estabelecimentos de ensino são fontes originais de pesquisa, pois é neles que os desafios são identificados e desenvolvidos mediante uma reflexão centrada nas atividades pedagógicas dos professores. (PARENTE, 2012, p.54)

Com isso, percebemos que o investimento na qualidade de ensino pode se dar tanto fora do ambiente escolar (através de pós-graduações, palestras, cursos complementares, etc.) como dentro do próprio âmbito escolar, na vivência com os alunos, em planejamentos e reuniões pedagógicas, através da execução de projetos e na troca de experiência com o corpo 
docente. É neste sentido que Libâneo (2004) reforça a importância da prática como geradora de experiência e igualmente enriquecedora, pois

É claro que os professores desenvolvem sua profissionalidade primeiro no curso de formação inicial, na sua história pessoal como aluno, nos estágios, etc. Mas é imprescindível ter-se clareza hoje de que os professores aprendem muito compartilhando sua profissão, seus problemas, no contexto de trabalho. É no exercício do trabalho que, de fato, o professor produz sua profissionalidade. Esta é hoje a idéia-chave do conceito de formação continuada. Colocar a escola como local de aprendizagem da profissão de professor significa entender que é na escola que o professor desenvolve saberes e as competências do ensinar, mediante um processo ao mesmo tempo individual e coletivo. (p. 34-35)

No entanto, atrelado ao entendimento da necessidade de qualificação para um ensino de qualidade existe a realidade profissional/social ao qual o professor está vinculado. Em um cenário geral temos, na maioria das vezes, salas de aula superlotadas, carga horária extensiva decorrente da necessidade de se acumular funções (a maioria dos professores acumula dois cargos ou tem jornada de trabalho dupla, em alguns casos tripla) em virtude da má remuneração. Assim, segundo Fontana (2005), em uma pesquisa realizada com algumas educadoras sobre a jornada de trabalho para seu livro "Como nos tornamos professoras?":

Nossos depauperados salários provocaram, em alguns momentos, lamentos em torno do fato de muitas de nós sermos obrigadas a 'dobrar', assumindo oito horas de trabalho diárias na escola (como o faziam duas professoras do grupo), ou mais outras quatro ou seis horas em casa, acompanhando crianças que, por algum motivo, não estavam dando conta sozinhas das atividades que a escola propunha e/ou impunha a elas (solução assumida por uma professora do grupo). (2005, p. 130)

Essa sobrecarga profissional, que acaba desgastando o profissional por falta de tempo/incentivo, pode inviabilizar ou dificultar seu aprimoramento profissional. No entanto engajar-se em uma postura de pesquisadora acaba sendo uma alternativa real para transformar a realidade da educação tendo em vista o tipo de profissional que se busca atualmente no mercado de trabalho, pois entende-se que não é viável para o profissional nem para os alunos ter aulas ministradas apenas com os conhecimentos adquiridos na graduação, deve-se buscar respaldos teóricos inovadores que sustentem e qualifiquem sua atuação. Segundo Freire (2009, p. 68), a meta “[...] não é parar de lutar mas, reconhecendo-se que a luta é uma categoria histórica, reinventar a forma também histórica de lutar”. 
Assim, mesmo diante de possíveis dificuldades, entende-se a necessidade de se reinventar, inovar, tornar o processo de ensino aprendizagem prazeroso e a ação eficiente, pois,

Trata-se de formar um profissional prático-reflexivo que se defronta com situações de incerteza, contextualizada e únicas, que recorre à investigação como forma de decidir e de intervir praticamente em tais situações, que faz emergir novos discursos e concepções alternativas de formação. (IMBÉRNON, 2005, p.39)

Existe uma gama de saberes inerentes à prática docente que se constrói no exercício cotidiano, estes tem seu valor e devem ser considerados, mas existe também outra gama de conhecimentos que se renovam cotidianamente, pois, como nos diz Santos "não há nem conhecimentos puros, nem conhecimentos completos; há constelações de conhecimentos" (2006, p. 154). Essa constelação de conhecimentos está sempre se renovando, devem estar sempre em pauta nas discussões relativas a educação e devem ser utilizadas para a melhoria das práticas pedagógicas e, consequentemente, da qualidade educacional.

\section{UM OLHAR SOBRE A FORMAÇÃO CONTINUADA DE PROFESSORES NA ESCOLA MUNICIPAL FÉLIX PEREIRA DOS REIS}

Dos oito professores que compõem o quadro geral do Ensino Fundamental II, todos possuem especialização. No entanto, a escola ou o poder municipal não oferecem cursos de capacitação ou aperfeiçoamento aos professores regularmente. O único tipo de formação de que a escola dispõe são os planejamentos quinzenais realizados na própria escola, com todos os professores, em conjunto. Sobre essas terminologias utilizadas (formação continuada, capacitação, aperfeiçoamento, etc.), Altenfelder (2005, p.18) nos diz que elas não são sinônimos, são concepções que direcionam ações distintas de formação. Assim:

Reciclagem, que é uma palavra usada no cotidiano para se referir a processos de modificação de objetos e materiais, não deve ser usada no contexto educacional, pois pode se referir a cursos rápidos, descontextualizados e superficiais, que não consideram a complexidade do processo de ensino.Treinamento também pode ser inadequado, se a educação continuada for pensada como um processo mecânico que meramente modela comportamentos.Aperfeiçoamento, entendido como um conjunto de ações capaz de completar alguém, de torná-lo perfeito, de concluí-lo, leva à negação da própria educação, ou seja, a idéia da educabilidade do ser humano.Capacitação, termo atualmente muito usado, pode ser congruente com a idéia de formação continuada, se considerarmos a ação de capacitar no sentido de tornar capaz, habilitar, uma vez que, para exercer sua função Revista de Pesquisa Interdisciplinar, v. 4, e4005, 2019. 
de educadora, a pessoa necessita adquirir as condições de desempenho próprias à profissão, ou seja, se tornar capaz.

Nesse sentido, entendemos que a formação continuada busca a constante capacitação dos professores, preparando-os para lidar, de maneira mais satisfatória, com as constantes transformações no campo educacional. No entanto, no munício de Santa Inês e na escola em análise, a capacitação é entendida pelos gestores como algo superficial, pois, o que pudemos observar pela análise dos documentos, o Censo Escolar e o Projeto Político Pedagógico, é que os professores da Escola Félix não encontram o respaldo institucional para adquirir este aprimoramento. Não consta na Secretaria de Educação do município, nem na escola, documento que registre algum tipo de formação ou investimento em capacitação profissional nos últimos anos.

No entanto, os professores, buscam através de empenho individual capacitar-se para o exercício da docência, uma vez que todos tem nível de especialista. Este empenho individual, entretanto, não exime a escola de um dos seus papéis, pois

Construção e transmissão do conhecimento devem ser entendidos como processos interdependentes que devem ser considerados de forma articulada e não excludente. Desse modo, a escola não deve ser concebida como um espaço que apenas cria condições ou favoreça a aprendizagem do aluno, mas sim, como instituição que planeja, organiza e se responsabiliza por essa aprendizagem (ALTENFELDER, 2010, p.36)

Assim, a escola é também responsável pela forma como a aprendizagem se dá, consequentemente é responsável pela formação/capacitação dos professores para que o aprendizado se dê de maneira significativa para os educandos. Quando, na Escola Félix Pereira dos Reis, não é oferecido aos educadores capacitação continuada, pensada de maneira a sanar as dificuldades existentes e melhorar a aprendizagem, e o único tipo de formação que se tem são planejamentos quinzenais descontextualizados e superficiais, corroboramos com Altenfelder (2010), pois, entendemos que o que existe é uma reciclagem dos profissionais, onde a educação não é vista em sua complexidade e dinamismo. A escola deve, pois, ter como objetivo um ensino capaz de formar cidadãos capazes de conviver e inferir de forma positiva na realidade onde vive.

Quanto às questões relativas ao Projeto Político Pedagógico (PPP) da escola, entendemos que este deve ser um documento de fácil acesso a todos os professores e que norteie as ações da equipe escolar. Para tal, o ideal é que este seja regularmente revisado no RPI Revista de Pesquisa Interdisciplinar, v. 4, e4005, 2019. 
intuito de atender as necessidades atuais da escola e que a comunidade participe também do seu processo de elaboração.

O atual PPP da Escola Félix é do ano de 2010 e não passou por revisão nos últimos anos. É um fator preocupante, já que reconhecemos as transformações constantes com o surgimento de novos conceitos e propostas, além das reformas nas políticas educacionais.

Mesmo quando existe uma atualização e constantes debates para o emprego dessas teorias, sua aplicabilidade não e totalmente eficaz devido à dicotomia existente entre teoria e prática. Como nos diz Perrenoud

As reformas escolares fracassam, os novos programas não são aplicados, belas idéias como os métodos ativos, o construtivismo, a avaliação formativa ou a pedagogia diferenciada são pregadas, porém nunca praticadas. Por quê? Precisamente porque, na área da educação não se mede o suficiente o desvio astronômico entre o que é prescrito e o que é viável nas condições efetivas do trabalho docente (2000, p.17).

Nesse sentido, pensar a teoria nem sempre é suficiente, pois se faz necessário pensar também a realidade social na qual ela será aplicada e sua funcionalidade. No entanto, o que pudemos observar a partir do PPP da Escola Felix Pereira dos Reis é que não existe, na comunidade escolar, debates e atualizações sobre as inovações teóricas e metodológicas do campo educacional, o que torna ainda mais distante uma possível adaptação das teorias existentes à realidade local.

O PPP também não aborda, detalhadamente, questões relativas à formação continuada dos professores, embora saibamos que existe uma diretriz específica para tal . Pensar a formação de professores de forma contínua, ao nosso ver, é uma das tarefas do Projeto Político da escola. Dos temas abordados encontramos metas, avaliação e metodologia, com referências ainda no ano de 2010. Sobre as metas, o PPP elenca:

Fazer monitoramento de todas as etapas contidas neste Projeto como:

1- Apoiar na divulgação do projeto;

2-Implementar projetos educativos a fim de beneficiar professores e alunos;

3-Planejar atividades de ensino de forma cooperativa;

4-Promover encontros de integração (atividades de lazer, conscientização) procurando cativar os pais a freqüentar a participar ativamente na vida escolar do seu/sua filho(a).

5-Buscar aprofundar conteúdos, metodologias para suprir as necessidades/dificuldades apresentadas pelos alunos durante o ano letivo;

6-Realizar reuniões bimestralmente;

7-Definir cronograma de execução do projeto;

8-Elaborar atas e relatórios periódicos, contendo informações de andamento 
9-Promover debates de conscientização a partir dos temas, autonomia, cidadania, participação, preconceitos raciais, divergência política, religiosa, financeira e outros que venham prejudicar ou afligir a dignidade humana e que esses pressupostos não se limitem a uma mera declaração de princípios registrada em documentos, mas que esteja presentes nas decisões tomadas pelo colegiado, na organização de eventos culturais, nas atividades cívicas, esportivas, recreativas e principalmente no planejamento de ensino.

O item do PPP de numero três, que diz que se deve planejar atividades de ensino de forma cooperativa, é o único que fala sobre o planejamento das atividades escolares na referida escola. Mas como é apresentado de forma superficial, não é abordado no documento estratégias, cronograma ou diretrizes para a sua realização.

Sobre os alunos, utilizamos dados do IDEB para analisar a avaliação da qualidade educacional na Escola Felix Pereira dos Reis. Esse exame padronizado mede o rendimento escolar nas etapas finais, e no nosso caso analisamos os dados sobre a turma de $9^{\circ}$ ano por meio da Prova Brasil e do SAEB (vide Anexo 3).

A média obtida no ano de 2017 pela Escola Felix Pereira dos Reis foi 3,5, com meta para o ano de 2019 de 3,7 e de 4,0 para o ano de 2021. O objetivo estabelecido pelo MEC para o ano de 2021, através do IDEB, foi de chegar a obter 5,5 pontos para os alunos dos anos finais do Ensino Fundamental. Nesse sentido, a escola ainda teria muito a avançar para atingir a meta estabelecida para o ano de 2021, e o investimento na formação de professores deveria, ao nosso ver, ser uma das ferramentas utilizadas para se atingir as melhorias desejadas na qualidade educacional, pois entendemos que a formação continuada do corpo docente deve estar baseada na promoção de mudanças significativas no interior da escola.

No entanto, reconhecemos que o aprendizado do alunado se dá de maneira ampla e perpassa os muros da escola, pois o universo cultural do aluno, e consequentemente seus conhecimentos, se expande através das relações com os diversos atores sociais que fazem parte do seu convívio. Nesse sentido, segundo Altenfelder

Pensar nessa direção significa, em nosso entender, considerar alternativas integradas e, assim, compreender que, para além da escola, existem outros espaços de aprendizagem que não são instâncias opostas e contraditórias a ela, mas que, muito pelo contrário, podem compor e complementar a educação escolar (2010, p.32).

\section{CONSIDERAÇÕES FINAIS}


Percebemos que pensar as questões relativas a educação e a formação de professores nos leva a debates amplos e enriquecedores, que tem como objetivo elevar a qualidade da educação. Assim, segundo Pimenta (1997, p. 23): “a importância que a qualificação profissional dos professores adquiriu nos últimos anos, no sentido de melhoria da qualidade do ensino, tem aprovado a ressignificação da didática" e consequentemente, a melhoria do processo de ensino-aprendizagem.

Quanto a formação de professores da Escola Felix Pereira dos Reis, concluímos que ainda existe um longo caminho a se percorrer no quesito das políticas educacionais de formação implementadas pela gestão escolar. Deve-se pensar, por exemplo, na implementação de meios que estabeleçam condições favoráveis para o acompanhamento e para a melhoria da rotina pedagógica da escola e, ainda, em condições favoráveis para a realização dos planejamentos, de cursos de formação e de acompanhamento pedagógico dentro da instituição.

Reconhecemos também que a escola possui um nível baixo de avaliação segundo as diretrizes do Ministério da Educação, e investir na qualificação profissional, aparece para nós como uma das formas de melhorar o rendimento escolar, pois mesmo reconhecendo que a construção de conhecimentos se dá nos mais variados espaços, vemos na escola, e na melhoria de suas práticas pedagógicas e organizacionais, um direcionamento para se avançar na construção de um ensino democrático e significativo. Com isso, sem a pretensão de solucionar os problemas existentes, esperamos contribuir com os debates acerca da formação de professores no município de Santa Inês- PB, e mais especificamente, com as questões relativas a Escola Felix Pereira dos Reis.

\section{REFERENCIAS}

ALARCÃO, I. Escola reflexiva e nova racionalidade. Porto Alegre: Artmed, 2001.

ALTENFELDER, Anna Helena. Desafios e tendências em formação continuada. Constr. psicopedag. São Paulo, v. 13, n. 10, 2005.

ALTENFELDER, Anna Helena. O papel da Olimpíada de Língua Portuguesa Escrevendo o Futuro no processo de formação continuada dos professores participantes. São Paulo: PUCSP, 2010. 
BRASIL, Constituição. Constituição da República Federativa do Brasil. Brasília: Senado Federal, 1998.

BRASIL. Lei $n^{\circ}$ 9394, de 20 de dezembro de 1996. Estabelece as diretrizes e bases da educação nacional. Brasília: Diário Oficial da União, 23 dez. 1996.

DEMO, Pedro. É preciso estudar. In A. M. de Britto. Memórias de formação: registros e percursos em diferentes contextos. Campo Grande: Ed. da UFMS, 2007

FONTANA, Roseli A. Cação. Como nos tornamos professoras? 3. ed. Belo Horizonte: Autêntica, 2005.

FREIRE, P. Pedagogia da autonomia: saberes necessários à prática educativa. São Paulo: Paz e Terra, 1996.

IMBÉRnON, Francisco. Formação Docente Profissional: Formar-se para a Mudança e a Incerteza. 2. ed. São Paulo: Cortez, 2005.

LIBÂNEO, José Carlos. Organização e Gestão da Escola: Teoria e Prática. Goiânia: Editora Alternativa, 2004.

MINAYO, M. C. S. (org). Pesquisa Social: teoria, método e criatividade. 28. ed. Petrópolis/RJ: Vozes, 2009.

PARENTE, Francisca Francirene Tomaz. Formação Continuada e Qualificação Profissional dos Professores de Sobral - CE: múltiplos olhares. Lisboa: Universidade Lusófona de Humanidades e Tecnologia Instituto de Educação, 2012.

PERRENOUD, P. A prática reflexiva no ofício do professor: profissionalização e razão pedagógica. Porto Alegre: Artmed, 2002.

PIMENTA, Selma G. O pedagogo na escola pública. São Paulo: Loyola, 1988.

PPP, Escola Felix Pereira dos Reis, 2010

SANTOS, B. S. A gramática do tempo. Para uma nova cultura política. São Paulo: Cortez, 2006.

SANTOS, B. S. Por uma concepção multicultural de direitos humanos. Coimbra-Portugal: Revista Crítica de Ciências Sociais. 1997. 